\title{
A SUGGESTED ROADMAP FOR WORLD-WIDE ENERGY RESOURCE PLANNING AND MANAGEMENT
}

\author{
R.G. BOOTHROYD \\ Chartered Engineer, Queensland, Australia.
}

\begin{abstract}
In the near future, we will need an internationally based system for worldwide planning of future energy resources and their effect on the world environment. Logically, this should be a responsibility of the United Nations, which already possesses much of the infrastructure needed and is already active in this area. Because different nations have different resources, different problems and different needs, it is reasoned that a flexible and diplomatic approach is also called for. We will need to try to secure support from all nations, and the economies and cultures of many nations differ considerably. This calls for special skills in negotiation. This is complicated by the varied, uncertain and changing technological facilities, which we have at our disposal. After a brief and comparative review of these facilities, an outline of the structure of the internationally coordinating organisation is suggested, followed by examples of the different types of issues which are likely to be encountered. These are: reintroducing improved technology to a nation, which has suffered grievous environmental harm from inadequate similar technology such as the Fukushima incident; nations with especially difficult transport problems; nations with perceived overpopulation problems; using UN and other expertise for nations still undergoing development; applying persuasive pressure by peaceful means. Finally, by outlining a large-scale cooperative venture by several nations, the mode of operation of the suggested U.N coordinating body is outlined. The example used is the choice of thorium-based molten-salt reactor technology using both fast and thermal neutron spectra. This appears to be the only choice we have, as other sustainable systems cannot accommodate the size of our problems. The only exception is using the Desertec solar project, which appears to be disadvantaged by being significantly more expensive. Molten-salt reactors would give a 1000-year energy security for industrialised energy-hungry nations on the Far East/Pacific Rim, which is the example considered. This system would use modern actinide burn-up technology to make nuclear-waste disposal a more acceptable proposition. Thus, nuclear waste can become a lowlevel and disposable hazard after only about 300 years of storage. After this storage, the waste becomes a valuable resource due to production of rare transmuted elements.

Keywords: actinide burn-up, climate control, molten salt thorium reactor, United Nations, fourthgeneration nuclear technology, 24/7 solar power.
\end{abstract}

\section{INTRODUCTION}

Few people would deny that provision of adequate energy resources for our world of the 21 st century is one of our most important concerns. Nevertheless, there are other concerns of vital importance. These include adequate provision of clean water; sufficient reserves of basic foods; welfare of all the various national economies; climate stability; maintenance of public health standards; world peace; employment, welfare and family income protection; human population control, maintenance of diversity in other species, etc. To some degree, these concerns are related to each other and adequate energy resources seem to be related to all of them.

A composite and broad approach is, therefore, necessary in organising the management of our world for the 21 st century and beyond. Energy resourcing is just one, albeit very important factor, among many others [1-8]. 


\section{CHOICE OF A MANAGEMENT SYSTEM}

The above needs limit our choice greatly. Only one organisation can handle such a range of responsibilities and this is the United Nations. Other organisations [10] can make useful contributions, but the ability to cope with the broad picture dominates the problem. The value of the UN also lies in its peace-keeping role because we face problems that require self-sacrifice among the parties involved. The most serious imminent problem we face is climate change and GHG emissions, and this affects us all. Figure 1 summarises the problem succinctly and it is well worth listening to the audio transcript [9], which advises us that we have no option but to leave much of our fossil fuels in the ground or use them very sparingly. Such resulting monetary concerns will stimulate serious dispute and disputes are best resolved at the UN level.

Figure 1, which is to logarithmic scale, illustrates in our own time the strong random natural temperature variations $\left( \pm 2^{\circ} \mathrm{C}\right.$ between ice-ages and hot spells) upon which we are now superposing our own anthropogenic effects from increasing GHG emissions. If we let world temperature rise just a few degrees more than natural balancing effects can control, we can easily experience runaway warming from release of methane into the atmosphere. The left side of Fig. 1 suggests that this would return us for a long time to the steamy climate of 50 million years ago. This sudden warming would come from release into our atmosphere of 'locked in' methane deposits, many of which are buried or kept stable under water. Already, in some parts of the world, we are experiencing the start of excessive release of deposited methane. The first released methane is 100 times more detrimental to our climate than $\mathrm{CO}_{2}$.

\section{AVAILABLE TECHNOLOGICAL RESOURCES, THEIR LIMITATIONS AND RESTRICTIONS RELATED TO THEIR USE}

Several popular texts [11-23] are available describing the various sustainable and nonpolluting energy resources, which are available to us. At least on a trial basis, most of these new technologies are worth incorporating into modern society even when they seem to be uncompetitive. Most new technologies are uncompetitive until engineers have had the practical experience to improve them.

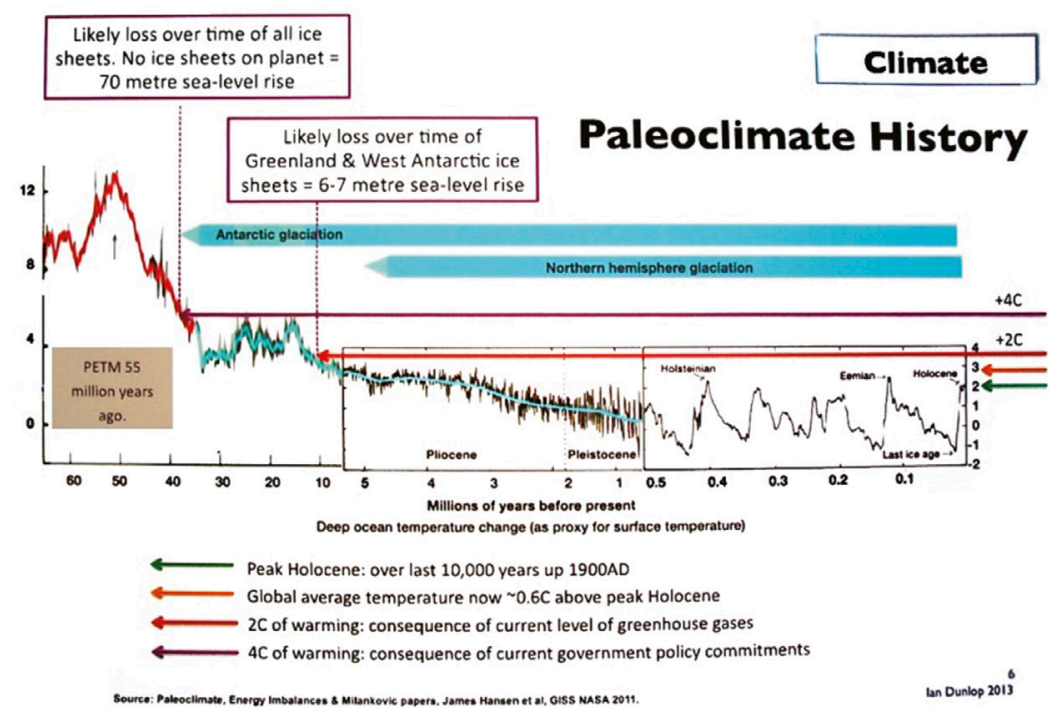

Figure 1: Earth's temperature fluctuations over 50 million years. From Ref. [9]. 
Yet, when we add all the new sustainable technologies together in toto, with just one exception (see the Desertec project below), they are insufficient to satisfy the needs of the modern world if we are forced to limit our use of fossil fuels significantly due to climate change. The reason is simple enough. Our world human population, already expected to reach 9 billion persons by 2050, is already far too large. When we consider that developing nations have aspirations similar to those already available to developed nations, the only way we can satisfy these needs is by more widespread use of nuclear power. Lovelock [24] has been researching this problem far longer than the present writer and has come to exactly the same conclusion [23, pp. 91, 92].

Many of our world's major problems are related to the size of our population. As just one illustrative example, Hook and Aleklett [25 ] have shown that it is not a feasible proposition to synthesise our liquid fuel requirements from our coal resources. Fortunately, we have not yet reached the need to consider this proposition because evidence for global warming seems to be a more immediate problem.

Adjusting the management of our world is a subtle business. For example, there seems to be an underlying conflict of interest between the human individual and our corporate structures [26]. The term 'corporate structures' is used here in its widest sense to even include democratic political parties and organised religion. Corporate organisations usually regard population increase and economic growth as in their best interest. On the other hand, the economic welfare of the individual is inversely proportional to a nation's population when the nation's assets approach their maximum value, which is the usual case today.

The conclusion is that we need to be wary of misusing advances in technology. For example, the 'Green Revolution' has been criticised for stimulating the Malthusian effect.

In this paper, we consider two possible solutions to maintaining adequate future energy supplies. These are developing the Club of Rome's 'Desertec' solar energy project [27-29] and the much less expensive molten salt (MSR) nuclear reactors. If we use these technologies merely in yet another reckless pursuit of economic growth, do we have any other possible solutions to fix our problems? On the face of it, the answer to this question seems to be a definite no! This conclusion is reached because there are limits, which are becoming increasingly apparent, as to what new technology can achieve.

\section{DEVELOPING THE WORLD'S FIRST MASS-PRODUCED NUCLEAR REACTOR}

In the last 60 years, the nuclear reactor industry has been beset with a very constraining basic weakness. Nuclear reactors have very low fuel costs but very high capital costs are incurred in their construction. It is hard to avoid this problem if adequate safety measures are met. Also, traditional designs using encapsulated fuel take many years to build. MSR technology [30-33] offers a most attractive investment opportunity to change this state of affairs. Even if global warming is less dangerous than is feared, MSR reactors have the potential to outcompete other more traditional forms of base-load electrical generators, even those using coal. The reasons are many and varied [33]. Among many other advantages, they operate at atmospheric pressure; they use a very effective heat transfer fluid enabling compact heat exchangers to be used; the design of the reactor can be varied within wide limits of size; they use smaller fissile inventories that can be easily 'topped up' as the reactor operates; they have excellent natural safety features in possessing automatic control, which also gives good load-following characteristics, etc. Perhaps above all, the fluoride salts used with the dissolved fuel do not suffer from radiation damage thus eliminating a host of such problems with earlier reactors. 
In short, they are much safer than reactors using older technologies (see Appendix I). This is good news for Japan, which has little option but to return to a better form of nuclear power (see Fuji reactor that is well described in the public media). German present policy is to abandon nuclear power after the Fukushima incident, but it is hard to see how it can afford not to renuclearise, unless it can develop the Desertec approach. Germany's climate is not particularly well suited to solar power and Germany has a large and power-hungry industrial base, which is essential for the well-being of the European Community. This is not to belittle Germany's spectacular contributions to photovoltaic technology, which has been very useful in improving these manufactured products in China.

Public prejudice against nuclear power is strong because accidents are intolerable [34]. Yet, even after Fukushima, Japan is coming to terms with the need for better nuclear technology as is evident from the Fuji reactor. In other cases, prejudice seems to be partly related to earlier political links such as at Chernobyl and Maralinga [35].

It is suggested that immediate attention be directed at deciding on a very basic simplified design of a 'once through' MSR, which is attractive for world markets. Such a concept would need a very thorough market survey into the needs of different nations so that the full advantages of mass production using modular technology can be achieved. The Fuji reactor, which is well documented in public literature such as Wikipedia, comes close to meeting this specification.

In Fig. 2, which is schematic to include several designs, this mass-produced universal reactor would omit item (RP) as on-line fuel reprocessing is complicated and still needs significant development work. Off-gassing of gaseous fission products (FPGR) would use conventional existing technology [36]. The continuous removal of strong ${ }^{135} \mathrm{Xe}$ poison is essential and this continuous off-gassing occurs naturally with MSRs. A thermal neutron spectrum using unclad graphite moderator would be used. Control is also by graphite (moderator) control rods, which are inserted to increase the power in this type of reactor. To guarantee a 30-year life of the graphite, temperatures $\mathrm{T}_{1}$ and $\mathrm{T}_{2}$ are $650^{\circ} \mathrm{C}$ and $500^{\circ} \mathrm{C}$, which

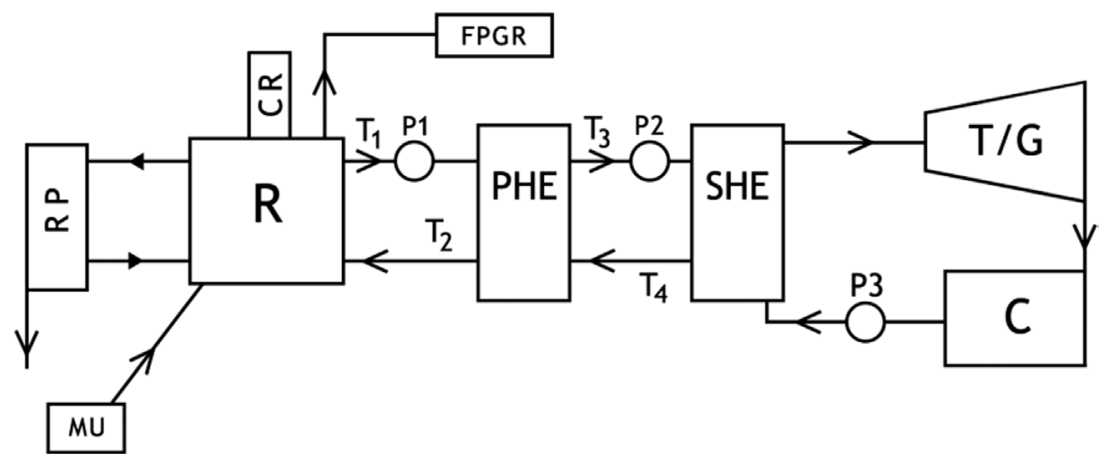

Figure 2: Schematic layout of the family of molten salt reactors. $\mathrm{R}=$ reactor; $\mathrm{RP}=$ on-line fission product reprocessing (if used); $\mathrm{CR}=$ graphite control rods (thermal reactor only); FPGR = fission product gas removal (mainly for ${ }^{135}$ Xenon poison); $\mathrm{PHE}=$ primary salt/salt heat exchanger; SHE = secondary salt/water heat exchanger; $\mathrm{T} / \mathrm{G}=$ power production; $\mathrm{C}=$ condenser; $\mathrm{MU}=$ top up of fissile material if $\mathrm{RP}$ not used; P1, P2 = molten salt pumps; $\mathrm{P} 3=$ feedwater pump; $\mathrm{T}_{1}-\mathrm{T}_{4}=$ molten salt temperatures. 
are slightly lower than in the Fuji reactor. It seems that an overall thermal efficiency of 35\% (with its resulting greater longevity of the graphite and the Hastelloy-N construction materials used) may be more attractive commercially, even though $35 \%$ is less than the $44 \%$ efficiency claimed for the Fuji reactor. This is because both thorium and uranium fuel costs are low and even a mass-produced nuclear reactor is a relatively expensive capital item. By using thorium in the fluoride salt mix, the reactor generates most of its own fuel requirements with very little topping up with low-enriched Uranium. This 'topping up' component (MU) replaces the RP unit shown in Fig. 2. Any fissile material can be used for topping up, although ample supplies of ${ }^{233} U$ are reported to be available [37]. The above estimates are only approximate and are not the result of extensive numerical optimisation methods [38].

It seems that this basic reactor system has the potential to become very profitable for a manufacturer. This would enable part of the resulting profits to be used to develop the RP unit in Fig. 2 needed in the more advanced designs expected to follow. These later reactors will now be considered in the order of expected priority for development and marketing.

\subsection{The two-fluid thermal breeder reactor}

The design of this reactor is significantly more complicated than the previous reactor. The reactor has a core similar to the previous reactor but this is surrounded by a thorium fluoride molten salt in a blanket. This blanket circuit is separated completely from the main core and a small bypass extracts continuously a small amount of the blanket molten salt. Fluorine is passed through this small amount of molten salt to extract the ${ }^{233} \mathrm{U}$ as gaseous uranium hexafluoride, which is created from thorium by neutrons.

The uranium hexafluoride is then reduced back to ${ }^{23} \mathrm{U}$ and a portion is returned to the reactor core to preserve the reactivity of the core. These reactors are breeders that produce more fuel than they consume. On-line fission-product extraction, item RP in Fig. 2, is feasible but needs considerable development.

The designers of the Fuji reactor recommend an alternative method of producing ${ }^{23} \mathrm{U}$ using a sub-critical assembly, which is a reactor that cannot go critical without an extra source of neutrons. One gigaelectronvolt protons are fired at a target in the sub-critical assembly causing spallation. Many neutrons are produced by each spallation incident and these breed ${ }^{233} \mathrm{U}$ from ${ }^{232} \mathrm{Th}$. It is claimed by the Fuji group that up to $450 \mathrm{~kg} / \mathrm{year}$ of $\mathrm{U}^{233}$ can be produced by this linear-accelerator technique. It remains to be seen, which thorium/233 $\mathrm{U}$ fuel breeding approach is to be preferred.

\subsection{The actinide burning fast reactor [39]}

In the fast reactor, the reactor vessel $\mathrm{R}$ in Fig. 2 is empty except for molten salt/fuel mix flowing through it. The fast reactor also generates most of its own fuel, but it also burns up the actinides such as Americium, Plutonium and Curium. This burn-up requires fast (energetic) neutrons. These actinides have very long half-lives, which make today's nuclear waste so dangerous. This reactor's extra function would be to eliminate the accumulated dangerous waste from earlier reactors to produce fission products with short half-lives so that the waste becomes relatively harmless after storing it for 300 years. This waste is also a valuable by-product and it is planned to extract valuable transmutation elements such as rhodium from it. Because ${ }^{233} \mathrm{U}$ has less neutrons than ${ }^{238} \mathrm{U}$ (the main constituent of natural uranium), the generation of actinides is much less in MSRs than in PWRs and BWRs. 


\subsection{The high-temperature MSR}

This reactor would depend on successful development of materials, which are superior to the Hastelloy-Nickel currently available[33]. This class of reactor has considerable value in the industrial world, which would experience serious setbacks due to any need to cope with climate change (see Appendix 1).

\subsection{The MSR family}

It is suggested that work on the reactor described in Section 4 should be started. If global warming is serious enough to require immediate mitigation measures, we will need large numbers of these reactors quickly as a stop-gap energy supply to avoid serious disruption of the world economy. These reactors would be designed for easy attachment to existing power station switch-gear so that nearby heavily polluting fossil-fuelled plant can be decommissioned quickly. There is even a strong case for stockpiling these reactors in anticipation of a climate change emergency, even before firm orders are placed. There is also an extra design consideration, which is important. This is to minimise the generation of greenhouse gases in the modular manufacturing process as much as possible, This is because it is likely that manufacturing restrictions may need to be imposed if we are faced with a sudden global warming crisis situation.

Reactors described in Sections 4.1-4.3 are required less urgently but are necessary to close the fuel cycle and enable the growing quantity of nuclear waste to be burnt up as a power source, resulting in nett waste with a low level of radioactivity after 300 years of storage.

These MSR reactors would enable us to achieve 1000-year security of available electricity in the forthcoming thorium nuclear age.

The reactor described in Section 4.3 depends on the success of the work of our nuclear metallurgists, but commercial pressures to develop this type of reactor are likely to become urgent sooner than development engineers would like.

\section{SOME RELEVANT CONCERNS RELATING TO RESOLVING ISSUES OF ENERGY USE AND AVAILABILITY}

Getting agreement between nations with widely different standards of living will be difficult. Also, many of our problems are sociological in nature rather than technical. Yet, some affluent nations have problems that often do not trouble less wealthy nations. Australia and the USA, for example, have long-distance travel needs and this is a large consumer of energy. The use of long-distance present-day diesel-powered trucking is very unsustainable [40]. Electrification of railways is only part of the answer because it cannot supply a comprehensive transport network to remote populations. Dependence on liquid fuels is hard to avoid, and alternative technologies [41] have limited attraction as an alternative to the high level of comfort and convenience of the present day.

In an urban environment, the use of electrical alternatives to liquid petroleum fuels offers more promise [42]. Whether this high-speed flywheel technology can ever be applied to heavy road transport using side road intermittent mobile charging from a rail is a matter of conjecture. An alternative airship approach was suggested [40] as a better solution.

Another area of contention between nations, which differ is that of unsustainable overpopulation. It has been argued that the Green Revolution has had adverse effects in stimulating a rise in population which may even increase poverty. It is encouraging, nevertheless, that 
statisticians have confirmed that excessive fertility correlates strongly with decreasing personal wealth. This in its turn suggests that higher levels of education and the emancipation of women in male-dominated societies are an effective natural remedy for overpopulation problems. The consensus of many experts is that world overpopulation is likely to be a temporary problem, but it is one which needs serious attention at present from the energy resource point of view.

Unemployment and weakening of welfare state benefits is presently more of a challenging concern in the affluent nations. In these nations, expensive human employment is progressively losing out to investment in more efficient automated machinery [28]. This trend is likely to extend to developing nations as employee expectations increase. It also seems likely that these developing nations will eventually need to provide a rudimentary form of welfare state if they are to avoid social unrest. All nations are likely to require a welfare state to be a contributory one for able-bodied people. Many socially necessary occupations are neglected now in advanced societies because labour costs are too high. Nevertheless, the ever-increasing trend towards automated manufacturing deserves support because it is usually more efficient in energy use and is less costly. Better technology creates more wealth and if we have sufficient wealth, and it is distributed equitably, who then needs a full-time job [28]?

A particular advantage, which is unique to the $\mathrm{UN}$, is that even the most powerful member nations can be criticised publicly for inadequate conduct by very well-informed critics. Such criticism is a humiliating experience for any nation, but it is probably more painful for larger and stronger nations. This form of persuasion can be a powerful form of non-destructive weaponry.

\subsection{The moral viewpoint}

Many publications make references to statements saying that we have so many years of such and such a resource available. This attitude has to be questioned. Surely, we have a duty to engineer schemes, which will preserve into perpetuity our beautiful world and its ability to support life. Greedy exploitation merely to make money at a cost to the future is an instinct, which needs to be condemned. It has been described as living on our capital instead of restraining ourselves to our available income.

In this respect, the difference between our species and other species is a most relevant factor. All forms of earthly life are subject to automatic control systems. The natural fluctuations of climate, illustrated in Fig. 1, are only a small part of this natural control system. Other components of earth's natural control system are predator/prey dynamics; fluctuating food/ resource dynamics, epidemic disease (which often results from overcrowding) and thermodynamic irreversibility/biological decay. We as a species are unique among the others in that we can alter many of these control systems. This ability may be our natural privilege but privilege in any civilised society brings with it responsibility. This particular responsibility is incumbent upon us all.

Whatever one's religious beliefs, if any, it is concluded that we have a sacred duty to all generations as yet unborn. This sacred duty is to leave our planet in a fit state for all forms of life. It is not morally acceptable to pillage our planet selfishly for monetary gain with no thought for the long-term future. We know how to love and cherish our children and grandchildren and plan for their welfare. Our descendants, in their turn, have the moral right to have access to the same experience. 


\section{SUGGESTED ORGANISATION OF THE COORDINATING BODY}

It is inappropriate to suggest how the UN should organise its energy resource management activities as this is its own particular forte. Present-day UN activities are adequately documented within the public domain. Just two points deserve some comments:-

When the comments in Section 1 are considered no less than 15, separate UN instrumentalities would be directly involved and many more are less directly involved. This suggests the need for some reorganisation.

Secondly, bearing in mind that UN responsibilities are likely to increase markedly in our troubled world [28], the question of future UN funding deserves comment. The fictional discussion in Appendix I would involve the UN in a 'fee for service', which is likely to be very profitable for the UN. However, such an activity would be an exception rather than the norm. Whereas it is inappropriate to even consider the UN as a form of world government, most of its activities are similar to that of any national government involved in public welfare. For this purpose, national governments have access to consolidated revenue from general taxation so that they can discharge their responsibilities. This suggests that a similar model for the UN would be desirable. Some forms of internationally based taxation are a matter of worldwide public interest. One such example is the oft-mooted [43] introduction of the Tobin tax on all international currency transactions. Powerful self-interested lobby groups have frustrated past attempts at introducing such a tax, which could be managed and used beneficially by the UN.

\section{ILLUSTRATIVE EXAMPLE OF UN PARTICIPATION IN MANAGING A LARGE ORGANISATION}

If, as seems to be so eminently reasonable, the UN becomes the World leader in managing our energy needs, then it will meet a variety of situations and problems. We need to examine some of them.

The worst of these problems is the exceptional uncertainty in our predictions related to the very nature of global warming. Control engineers when they are faced with an instability problem in a machine are well aware of the complexity, which often arises in redesigning the machine to get round the problem. Because physical processes in the world's atmosphere are so complicated with many interacting factors [44], we are presented with just such a dilemma. Would instability, which is apparently possible when considering Fig. 1, be one which we can correct or would it suddenly become an unrectifiable disaster if we continued to burn large quantities of fossil fuels as long as possible? It seems that we cannot provide a definitive scientifically derived answer to such a question at this time. Would we get sufficient warning of a looming instability-based disaster?

It seems that the best form of insurance, short of making immediate and radically painful changes to our society, is to have a plan for coping with just such a contingency.

The largest contributor to global warming is the use of fossil fuels to generate electricity. The next largest contributor is the burning of fossil fuels for transport and because of its size, surface transport is a bigger contributor than aviation transport. Ideally, aviation transport should not emit $\mathrm{CO}_{2}$ at high altitudes and hydrogen propulsion is better [45]. At present, liquid fossil fuels are considered essential for the transport industries but there are possible solutions to replacing liquid fuel energy with electrical energy [40-42]. This is considered the justification of the above-suggested policy of replacing the generation of electricity by fossil fuels with a massive expansion of nuclear-fission generated electricity. Appendix I digresses into the detail of likely consequences of such a policy. 


\section{CONCLUSIONS}

1. The molten salt nuclear reactor, in fast and thermal neutron spectrum forms, appears to be a unique and vital factor in returning our planet to a state of near-equilibrium.

2. The United Nations is the only organisation, which is suited to managing the task of solving our energy problems. Energy management is just one of such tasks envisaged for the UN.

3. The difference between our species and other species is a relevant factor.

All forms of earthly life are subject to automatic control systems. The natural fluctuations of climate, illustrated in Fig. 1, are only a small part of this natural control system. Other components of earth's natural control system are predator/prey dynamics; fluctuating food/resource dynamics, epidemic disease and thermodynamic irreversibility/biological decay. We as a species are unique among the others in that we can alter these control systems. This ability may be our privilege but privilege in any civilised society brings with it the responsibility of controlling ourselves.

4. Finally, it is concluded that there are limits to the ability of scientists to solve many problems now faced by our scientifically advanced society. It seems to be folly to ignore such problems in the unsubstantiated belief that 'someone' will 'somehow' and 'somewhere' find a solution.

\section{APPENDIX I}

In Section 4, it was stated that we need to expand our use of commercial nuclear power. First, we need to look at an extra bit of recent history in addition to the history, which is already in print $[30,32,33]$.

The strange story of commercial nuclear power

Sixty years ago we had more than a thousand different concepts [30] for designing a nuclear power station. Today, we still have a massive range of choices [46]. It all seemed so obvious to young nuclear scientists 60 years ago. Inevitably, we would produce a most toxic form of poison from the fission products so it seemed clearly necessary to encapsulate the fuel and its poisonous fission products in a most reliable container, which we called the fuel element. A fortune in research funding was spent on encapsulating this difficult fissile material, which produced acute radiation damage. Eventually, the problems were solved reasonably well with oxide fuels and a zirconium alloy jacket. Also, although we were well aware that thorium was a far superior and more abundant fuel than uranium, our bosses were obsessed with making ${ }^{239}$ Plutonium for bombs, and this needed a natural uranium fuel. It seemed obvious to many young scientists at the time that these atomic bombs were a rather impractical and unusable form of weaponry. ${ }^{233} \mathrm{U}$ atomic bombs were actually made from thorium after converting it to explosive ${ }^{233} \mathrm{U}$ from neutron irradiation. However, this also produced another isotope ${ }^{232} \mathrm{U}$, which was so radioactive with hard gamma radiation that it was impossible to use these bombs.

However, much of the blame for making bad choices must be shared with the young scientists of the time. Most of us dismissed the work in the 1960s in developing a molten salt nuclear reactor as an idea, which was unlikely to 'catch on' because the fuel and its fission products were combined to give a very novel but lethally radioactive coolant. This seemed to raise a host of other problems. In this belief, we were grossly mistaken. Even young scientists can get caught in a mind-set when they get accustomed to using established methods. The 
nett result is that today we are stuck with a huge investment in an outdated nuclear technology of PWRs, BWRs and sodium or lead fast breeder reactors. Only good engineering and perhaps a bit of good luck has restricted our bad accidents to Three Mile Island, Fukushima and Chernobyl.

The thorium/molten salt reactor

Today, with the benefit of hindsight, we can see our way forward and MSR technology is vital as we see the problems of GHGs looming ever closer to us. The advantages of the molten fuel reactor system are numerous and well documented [47]. Youtube presentations are an excellent way to see the advantages of this system. Many of these other very informative audio-visual presentations can be accessed through Ref. [47]. A more detailed review of the latest developments in MSR technology is planned for a later paper.

The clearest and shortest way to demonstrate how the UN coordinating body could function is to use a fictional account from memoirs written by someone who has worked on energy-related problems and is now living some 30 years into the future. Some present-day references are included to help the reader 'flesh out' the text. Predictions into the future are notoriously unreliable but at least there are some alternative predictions worthy of consideration [48]. The discourse presented here is not intended to be alarmist. Some very alarmist predictions have been reported elsewhere [49] recently.

Fictional 'memoirs' of an ageing scientist/engineer written in 2050

......It all seemed to start in early 2015 when the price of a barrel of oil fell from $\$ 100$ to $\$ 50$ as the new unconventional oil resources entered an oversupplied market. Such sudden price fluctuations had happened before and there was a happy feeling of complacency among "consumers' that the 'law of supply and demand' could be seen to work both ways. However, industrial entrepreneurs in the new Far Eastern economies were far from complacent. They foresaw a future where a commodity such as energy needed price stability if their recent expensive investments were to thrive or even survive.

Then, we experienced ocean flooding problems in low-lying islands. The unfortunate people of the Maldives could not find a refuge in a world, which was now becoming incapable of coping with the size of yet another large refugee problem. Significant loss of life and property due to a more extreme climate was experienced later in the Bay of Bengal. Finally, the UN was forced to take drastic action when simultaneous worldwide crop failures from drought in the U.S, Ukraine and Europe generally, together with unexpected severe flooding in Australia followed by a mouse and locust plague, brought the threat of famine to millions.

It was resolved that a drastic and miserly capitation-based ration of $\mathrm{CO}_{2}$ emission had to be accepted by all nations. One important factor in their decision was the fact that the 'Green revolution' now supported five out of six of the World's population. The Green Revolution relied on the massive production of ammonia fertiliser manufactured from natural gas, which added to GHG emissions. The ensuing partisan arguments in the UN General Assembly were very bitter. Affluent nations resisted the UN, motion seeing that their economies would be severely damaged. Less-developed nations wished to drag themselves out of their grinding poverty now bordering on mass starvation. The situation was so serious that a hastily conceived compromise capitation emission allowance was accepted, based on the population of each nation over the age of 25 . From the date of the UN resolution, it was agreed that no allowance could be made for any changing circumstances [50,51]. 
Affluent nations on the Pacific Rim had recognised much earlier that a rapid investment in nuclear power was essential. It was also recognised that the problem with conventional nuclear power plants is that they take too long to build in an emergency situation. The only viable large-scale alternative sustainable solution was the CST solar power station, which could be built in sufficient numbers in desert areas [28]. However, the few existing CST plants were expensive generators producing electricity at 10-12 cents/kWh, which compared unfavourably with nuclear plant generating at less than half this cost. Also, the necessary extremely long HV/DC transmission lines needed would add to the cost of solar power.

Pacific Rim nations decided to cooperate with each other using a senior UN facilitator as their Chairman together with his staff of nuclear engineers all of whom were chosen as experienced in the art of negotiation.

India, Australia and the United States have the largest thorium resources and a modular design of molten liquid thorium reactor (Section 4 and Fig. 2) was selected for mass production. Each nation would manufacture components for the universal standardised reactor design all of which were planned to be operational plants within 3 years. Australia was among the hardest of member nations to be hit financially because all its base-load power plants were coal-fired. Also, it had lost its fossil fuel exports and with its uncompetitive manufacturing economy was already facing economic disaster becoming deskilled to the extent of seeing its best technology graduates moving overseas for employment. It was given the responsibility of making CST technology more competitive as a back-up programme just in case the nuclear expansion program was less successful than had been hoped.

This was a significant task as there are problems with CST solar technology such as how to cope with molten salt in a long riser pipe [52] when a molten-salt pump needed replacement. Even the problem of keeping heliostats clean in a dry dusty environment can be troublesome. Because CST and MSR both use molten salts, although the salts used are completely different, it seemed that CST practice could benefit from copying MSR methods. An MSR reactor uses a frozen safety plug in the base of the reactor, which unfreezes in the event of a power failure. It has been reported [53] that it is difficult to design maintenance shut off valves for molten salt CST systems. Designwise, this approach seemed unnecessary: it seemed logical to nest clusters of redundant pipe circuitry together so that they keep each other hot. When shutdown of a particular circuit is required, portable freezing equipment can be used to isolate the particular circuit under repair with two temporary frozen plugs. Good safety gear is required for this class of maintenance work but it is no more difficult than that experienced in a typical steelworks or foundry.

Each nation was left to decide its own policies in meeting these demanding emergency emission standards of the UN. Some people had just listened to the media-borne political platitudes and only expected to find no aluminium foil on the supermarket shelf. They were taken by surprise. Many nations had no option but to eliminate private motoring completely. Vehicles in their millions lay rusting away all over the world. Backyard swimming pools of the more opulent citizens became muddy mosquito-infested ponds now found useful for water storage so that backyard vegetables could be grown. Bicycle manufacturers had problems keeping up with demand, and many people were envious of their neighbours who could still afford the new folding lithium-ion motor scooters [41] to access overcrowded public transport. This saga of misery amongst once comfortable people was most painful. Nevertheless such hardship was miniscule compared with the hunger and poverty in less fortunate parts of the world.

Now more than 30 years from this era of suffering, all the mass-produced type 1 MSRs described in Section 4 are still working beyond their planned lifetime, a testimonial to the 
modest specifications used in their design. By contrast, the latest type 10 MSRs are vastly superior, achieving nearly 50\% thermal efficiency. They use an integrated generating system incorporating a Brayton cycle gas turbine unit feeding hot exhaust to a supercritical steam cycle. These reactors, where the neutron spectrum can be fast or thermal, can be configured to breed more fuel than they consume or used to burn up the long-lived nuclear waste from old-fashioned PWRs and BWRs. Some nations are even competing to be allowed to store the waste from these reactors so that valuable by-product materials can eventually be extracted from the waste.

The Pacific Rim Consortium is now amongst the most wealthy of global corporations. It has just announced its latest creation. This is a molten salt high-temperature reactor generating hydrogen as well as power. It makes ammonia fertiliser using a form of the Haber-Bosch process from air, water and electricity. Useful by-products are pure oxygen and argon. The reactor is just a part of an industrial complex as large as a small town and it does not employ a single person! Each component control computer submits reports to the central control computer, which makes all decisions including any decision to call for quotations for maintenance work. The central computer then checks this work of its contracted human employees and pays for it automatically. These maintenance-staff are the only people to see the inside of the plant. All this was made possible by the patented special materials developed by the Consortium, which no longer uses much Hastelloy $\mathrm{N}$ in its components.

There are plans to use these new reactors in other huge industrial complexes. One of these plans is to locate the reactor close to a cement manufacturing plant and other industries which emit large quantities of $\mathrm{CO}_{2}$. Using this $\mathrm{CO}_{2}$, the plant would be used to make dimethyl ether as a diesel fuel in addition to products such as methanol. This is a feasible method of cleansing the atmosphere of $\mathrm{CO}_{2}$ although it is only small-scale compared with decades of GHG contamination. The actual nett atmospheric cleansing is from the slow curing of concrete made from the cement which slowly absorbs atmospheric $\mathrm{CO}_{2}$. At least, this technology will enable heavy industry to redevelop until we can start to use petroleum products again.

The Pacific Rim Consortium has had its problems. The worst of these was when North Korea petitioned the UN to join the Consortium. The United States and South Korea threatened to leave but the UN facilitator knew well enough that either India or China individually had the industrial capacity to lead the project. Anyway, the Facilitator pointed out that it was not normal policy for the UN to question a member nation's political system. He also pointed out that North Korea had offered the valuable services of several of their nuclear experts. Mindful of the loss of future profit involved in leaving the Consortium, agreement was finally restored with appropriate concessions such as North Korea signing the Nuclear Non-Proliferation Treaty. Today, this ill feeling may remain but it is never considered seriously because of the huge increase in trade between these three member nations. The last 30 years may have been painful but we have had our joyous moments of achievement.

The thorium nuclear age is predicted to last 1000 years, which should be sufficient for us to design a more rational world for our descendants...

\section{APPENDIX II: NOMENCLATURE}

BWR boiling water reactor (similar in many ways to a PWR)

CST concentrating solar tower [27-29]

GHG greenhouse gas 
HV/DC high-voltage /direct current (a more efficient but more complicated method of grid electricity transmission when long distances are involved)

MSR molten salt nuclear reactor

PWR pressurised water reactor - a commercial derivation of the reactor used in the Nautilus, the first nuclear submarine

\section{REFERENCES}

[1] Hiscock, G., Earth Wars: The Battle for Global Resources, John Wiley: Singapore, pp. 1-285, 2012.

[2] Walther, J.W., Earth's Natural Resources, James \& Bartlett: Burlington, MA, pp. 1-428, 2014.

[3] Speth, J.G., The Bridge at the End of the World, Yale University Press: New Haven, pp. 1-295, 2008.

[4] Ackerman, F., Can We Afford the Future: The Economics of a Changing World, Zed Books: London, pp. 1-151, 2008.

[5] Nicholson, M., Energy in a Changing Climate, Rosenberg: NSW, Australia, pp. 1-232, 2009.

[6] Giampietro, M. \& Mayumi, K., The Biofuel Delusion: The Fallacy of Large-Scale Agro-Biofuel Production, Earthscan: London, pp. 1-318, 2009. doi: http://dx.doi. org/10.4324/9781849770200

[7] Stevens, C.V. \& Verhe, R. (eds), Renewable Bioresources: Scope and Modification for Non-Food Applications, John Wiley: Chichester, UK, pp. 1-310, 2004.

[8] Mirza, M.M.Q. \& Ahmad, Q.K., Climate Change and Water Resources in South Asia, pp. 1-322, 2005. doi: http://dx.doi.org/10.1201/9780203020777

[9] Dunlop, I., Peak oil, climate change and global sustainability - the case for emergency action, ASPO-Australia.org.au

[10] Pebble, R. (ed.), World Energy Outlook 2010, International Energy Agency: Paris, pp. 1-731, 2010.

[11] Van den Burgh, J.C.J.M. \& Bruinsma, F.R., Managing the Transition to Renewable Energy, Edward Elgars: Cheltenham, UK, pp. 1-385, 2008.

[12] Blackburn, W.R., The Sustainability Handbook, Earthscan: London, pp. 309-371, 2008.

[13] Bossell, H., Earth at the Crossroads: Paths to a Sustainable Future, Cambridge University Press: pp. 1-338, 1998.

[14] Vincent, D., Arresting carbon dioxide emissions: why and how, Evidence for Global Warming, eds. F. Armstrong \& K. Blundell, Oxford University Press, pp. 13-15, 2007.

[15] Nersesian, R.L., Energy for the 21st Century: A Comprehensive Guide to Conventional and Alternative Sources, M.E. Sharpe: New York, NY, p. 402, 2007.

[16] Randolph, J. \& Masters, J.M., Energy for Sustainability - Technology, Planning, Policy, Island Press: Washington, DC, pp. 1-790, 2008.

[17] Wilson, J.R. \& Burgh, G., Energising Our Future:Rational Choices for the 21st Century, Wilet-Interscience: New York, NY, pp. 1-390, 2008.

[18] Sorensen, B., Renewable Energy: Its Physics, Engineering. Use, Environmental Impacts, Economy and Planning Aspects, 3rd edn., Elsevier: Amsterdam, pp. 1-928, 2004.

[19] Coley, D., Energy and Climate Change: Creating a a Sustainable Future, John Wiley: Chichester, UK, pp. 1-656, 2008.

[20] Siegfried, D. \& Witzel, W., Renewable Energy: The facts, Earthscan: London, pp. 1-251, 2010. doi: http://dx.doi.org/10.4324/9781849775298 
[21] Ruddiman, W.F., Earth Transformed, W. H. Freeman: New York, NY, pp. 1-375, 2014.

[22] Jaccard,M., Sustainable Fossil Fuels, Cambridge University Press, pp. 1-381, 2005.

[23] Morris, C., Energy Switch: Proven Solutions for a Renewable Future, New Society: Gabrioli Island: Canada, pp. 1-207, 2006.

[24] Lovelock, J., The Vanishing Face of Gaia: A Final Warning, Penguin: London, pp. 1-177, 2010.

[25] Hook, M. \& Aleklett, K., A review on coal to liquid fuels and its coal consumption, Int. J. Energy Res., 34, pp. 848-864, 2010. doi: http://dx.doi.org/10.1002/er.1596

[26] Boothroyd, R.G., Let's have a new Wiki for a free flow of information. Australian Rationalist, 81(4), pp. 41-45, 2008.

[27] Desertec Foundation, www.desertec.org/concept/questions-answers

[28] Boothroyd, R.G., Urban planning for emergent technologies, new life styles and a changing environment. WIT Transactions on Ecology and the Environment, 179, pp. 93-107, 2013. doi: http://dx.doi.org/10.2495/sc130081

[29] Wright, W. \& Hearps, P. (lead authors), et al., Zero Carbon Australia Stationary Energy Plan, 2nd edn., University of Melbourne Energy Research Institute: Australia, pp. 1-171, 2011.

[30] Hargraves, R. \& Moir, R., Liquid fluoride thorium reactors. American Scientist, 98(4), pp. 304-313, 2010. doi: http://dx.doi.org/10.1511/2010.85.304

[31] Shiga, D., Rescuing nuclear power. New Scientist, 209(2805), pp. 8-10, 2011.

[32] LeBlanc, D., Too good to leave on the shelf. Mechanical Engineering, 132(5), pp. 28-33, 2010.

[33] Forsberg, C.W., Thermal- and fast-spectrum molten salt reactors for actinide burning and fuel production, Dept of Energy, Oak Ridge National Laboratory, Work No. G-OR 07MS0101 (Amer. Nuc. Soc. MS \# 175768, 2017, Boise, Idaho), 2007.

[34] Christodouleas, J.P., Forrest, R.D., Ainsley, G., Tochner, Z. \& Hahn, S.M., Current concepts: short-term and long-term health risks of nuclear power plant accidents. New England Journal of Medicine, 364(24), pp. 2334-2341, 2011. doi: http://dx.doi. org/10.1056/nejmra1103676

[35] Walker, F., Maralinga: The Chilling Expose of Our Secret Nuclear Shame and Betrayal of Our Troops and Country, Hatchette: Sydney, pp. 279-289, 2014.

[36] Soelberg, N.R., Garn, T.G., Greenhalgh, M.R., Law, J.D., Jubin, R., Strachan, D., M. \& Thallapally, P.K., Radioactive iodine and krypton control for nuclear fuel reprocessing facilities. Science and Technology of Nuclear Installations, Article ID 702496, 2013. doi: http://dx.doi.org/10.1155/2013/702496

[37] Alvarez, R., Managing the uranium-233 stockpile of the United States. Science and Global Security, 21, pp. 53-69, 2013, doi: http://dx.doi.org/10.1080/08929882.2013. 754311

[38] Fiorina, C., Cammi, A., Luzzi, L., Mikityuk, K., Misachi, N. \& Ricotti, M.E., Thermal hydraulics of internally heated molten salts and application to the molten salt reactor. Journal of Physics: Conference Series, 501, 012030 2014. doi: http://dx.doi. org/10.1088/1742-6596/501/1/012030

[39] Ignatiev, V.V., Feynberg, O.S., Zagnitko, A.V., Merzlyakov, A.V., Surenkov, A.I., Panov, A.V., Subbotin, V.A. \& Kormilytsin, M.V., Molten salt reactors:new possibilities, problems and solutions. Atomic Energy, 112 (3), pp. 157-165, 2012. doi: http://dx.doi. org/10.1007/s10512-012-9537-2 
[40] Boothroyd, R.G., A proposed Australian transition to an anhydrous ammonia fuel transport economy to replace liquid petroleum fuels. WIT Transactions on Ecology and the Environment, 186, pp. 443-456, 2014. doi: http://dx.doi.org/10.2495/esus140381

[41] Boothroyd, R.G., Replacing the private car with a more attractive public transport system, Paper 1061, General Proceedings, 12th World Conference on Transport Research, Lisbon, 2010.

[42] Boothroyd, R.G., Energy resources for transport: political apathy and neglect - an Australian experience. WIT Transactions on Ecology and the Environment, 190, pp. 637-650, 2014. doi: http://dx.doi.org/10.2495/eq140611

[43] Boyle, N., 2014: How to Stop the Next World Crisis, Continuum International: London, pp. 93-96, 2010.

[44] Hansen, J., Storms of My Grandchildren, Bloomsbury: New York, NY, pp. 1-303, 2009.

[45] Boothroyd, R.G., A proposed extra international air corridor along the world's equatorial belt, Paper 1067, General Proceedings, 12th World Conference on Transport Research, Lisbon, 2010.

[46] Poullikkas, A., An overview of future sustainable nuclear power reactors. Int. J. Energy Environ., 4(5), pp. 743-776, 2013.

[47] Greaves, E., A new paradigm: thorium as nuclear fuel in the molten salt reactor, https;// www.youtube.com/watch?v=vBIyZZuQ14A

[48] Martin, R., Thorium: the Green Energy Source for the Future, Palgrave Macmillan: New York, NY, pp. 1-257, 2012.

[49] Marshall, M., World changing, New Scientist, 225(3002), pp. 34-37, 2015.

[50] Anonymous, Energy Balance of OECD Countries (2010 edn), IEA: Paris, pp. 1-249, 2010.

[51] Anonymous, Energy Statistics of OECD Countries (2010 edn), IEA: Paris, pp. 1-326, 2010.

[52] Deign, J., http://social.cspttoday/technology/molten-salt how-to-avoid-big freeze

[53] Abengoa Solar, Sunshot Conference, Project Review energy.gov/sites/prod/files...cap review_meeting_042413_grogan.pdf 